\title{
9
}

\section{CÁUCASO SUR, UNA REGIÓN DESCONOCIDA A LAS PUERTAS DE EUROPA}

El Cáucaso Sur es una región situada entre Europa y Asia Central, conformada por tres Estados: Armenia, Azerbaiyán y Georgia. Mientras que Armenia y Georgia son considerados por el Banco Mundial como países de ingreso bajo, Azerbaiyán, gracias a detentar elevadas reservas petrolíferas, es un país de ingresos medio alto. La Unión Europea se ha convertido en el principal socio comercial de estos Estados, y la Comisión Europea está intentando facilitar un incremento de los lazos económicos y políticos con estas repúblicas mediante la implantación de diferentes acuerdos y programas.

Palabras clave: relaciones económicas UE-Cáucaso del Sur, previsiones, intercambios comerciales, política europea de vecindad, Unión Económica Euroasiática.

Clasificación JEL: F00, F13, F36.

\section{Introducción}

Este artículo pretende presentar de forma clara las relaciones económicas existentes entre la Unión Europea (UE) y los Estados que conforman el Cáucaso Sur: Armenia, Azerbaiyán y Georgia. Tanto Osetia del Sur y Abjasia en el caso georgiano como la región del Nagorno-Karabaj en el caso azerí no serán tenidas en cuenta, pese a su independencia de facto, al no ser reconocidas como Estados por parte de la Unión Europea.

Pese a tratarse de un estudio de marcado carácter económico, no es posible tratar la

\footnotetext{
*Graduado en Historia e Indi por SOAS, Universidad de Londres. Colaborador-Becario en el Ministerio de Asuntos Exteriores y Cooperación.

Versión de agosto de 2017.
}

economía regional sin enmarcarla en su contexto histórico-político. Por ello, el desarrollo de las relaciones económicas se presentará acompañado de las circunstancias políticas en las que éstas tuvieron lugar.

Los países del Cáucaso Sur están rodeados de potencias que históricamente se han disputado el control de la región. Irán es uno de los Estados vecinos que mayor influencia ha tenido, ya que distintas dinastías radicadas en lo que hoy es Irán han controlado gran parte del territorio del Cáucaso Sur. Turquía es la segunda nación vecina que ejerce una influencia significativa, ya desde tiempos del Imperio Otomano. Cabe destacar que las relaciones entre Turquía y Armenia son prácticamente inexistentes, al negarse Turquía a reconocer el genocidio de aproximadamente millón y $\triangleright$ 
medio de armenios durante la Primera Guerra Mundial. Asimismo, el actual Estado turco ocupa territorios tradicionalmente armenios. Valga como ejemplo el monte Ararat, símbolo nacional armenio y hoy en Turquía. Pero será el tercero de estos Estados, Rusia, quien mayor influencia atesora en la región. Desde la expansión de la Rusia imperial en la región, a lo largo del siglo xIX, su presencia alteró el equilibrio de poder en la zona, y tras una brevísima independencia, los Estados del Cáucaso Sur pasaron a formar parte de la Unión Soviética. Como se verá en el presente artículo, los efectos de las siete décadas de Gobierno soviético han dejado una profunda huella en estos países. La influencia rusa se pudo ver en su forma más brutal en la corta y desigual guerra entre Georgia y Rusia en 2008, lo que provocó un desmembramiento de Georgia que pervive en la actualidad.

Las relaciones entre los tres países varían considerablemente. El caso más evidente de las tensiones entre estos países es el conflicto por el Nagorno-Karabaj entre Armenia y Azerbaiyán. El legado económico, político y social, tanto de las décadas de gobierno soviético como del rápido desmoronamiento de éste, sigue presente en la región, afectando profundamente el funcionamiento de estos Estados. A continuación se hará un breve repaso al acercamiento económico de Armenia, Azerbaiyán y Georgia a la Unión Europea desde la década de los noventa hasta la actualidad.

\section{Armenia}

Desde la caída del régimen soviético, las relaciones entre la Unión Europea y Armenia han vivido un progresivo acercamiento tanto político como económico, acercamiento, eso sí, condicionado por el papel de Rusia como principal aliado de Armenia. Pese a un notable sentimiento europeísta, la situación geográfica armenia, entre dos Estados hostiles como son Turquía y Azerbaiyán, impone un realismo que conduce a la situación actual de alianzas políticas del pequeño Estado caucasiano.

De acuerdo con la información disponible en Databank del Banco Mundial, Armenia es un país de ingreso mediano bajo. Con casi tres millones de habitantes, medio millón menos que en 2009, en 2016 el PIB armenio era de 10.547 millones de dólares. Su renta per cápita ${ }^{1}$ es de 3.700 en dólares corrientes y de 9.000 millones de dólares en paridad de poder de compra, una cuarta parte del poder adquisitivo de los españoles, lo que supone menos del 10 por 100 del PIB español.

Una tercera parte de la población vive en Ereván, su capital, y la edad media del país es de 34,6 años, según la Central Intelligence Agency (CIA).

Este bajo nivel de desarrollo también se evidencia en su estructura productiva. La agricultura tiene un peso significativo, ya que supone casi el 20 por 100 del PIB y el 36 por 100 del empleo; la industria aporta el 29 por 100 del PIB y el 17 por 100 del empleo; y los servicios el restante 51 por 100 del PIB y alrededor del 47 por 100 de la ocupación (CIA, 2017).

La tasa de paro es elevada, cercana al 18 por 100, y un tercio de su población está por debajo de la línea de la pobreza. La inflación en Armenia, después de sufrir tensiones al alza desde mediados de la pasada década, se ha moderado en los últimos años y las últimas previsiones del FMI apuntan a un aumento de los precios del $\triangleright$

1 INB per cápita, método Atlas (USD a precios actuales), Banco Mundial. 
2 por 100 en 2017 y del 3,5 por 100 en 2018. El déficit público fue del 5 por 100 en 2016, con una baja proporción de ingresos públicos, alrededor del 23 por 100 del PIB (FMI, 2017).

Respecto a sus intercambios con el exterior, según el FMI, Armenia ha ido reduciendo paulatinamente su déficit por cuenta corriente en la década actual, al pasar de -16,5 por 100 en 2009 a menos de un 3 por 100 en los dos últimos años. Este organismo espera que el déficit por cuenta corriente sea el equivalente al 3,2 por 100 del PIB en 2017 y del 2,9 por 100 en 2018.

El valor de sus exportaciones de bienes en 2016 fue de 1.610 millones de dólares, básicamente de materias primas: minerales y productos agrícolas. Dejando aparte países de la UE, sus principales destinos son Rusia (15 por 100 del total), China (11 por 100), Iraq (9 por 100) y Georgia (8 por 100). Por su parte, el valor de sus importaciones de bienes fue de $2.974 \square$

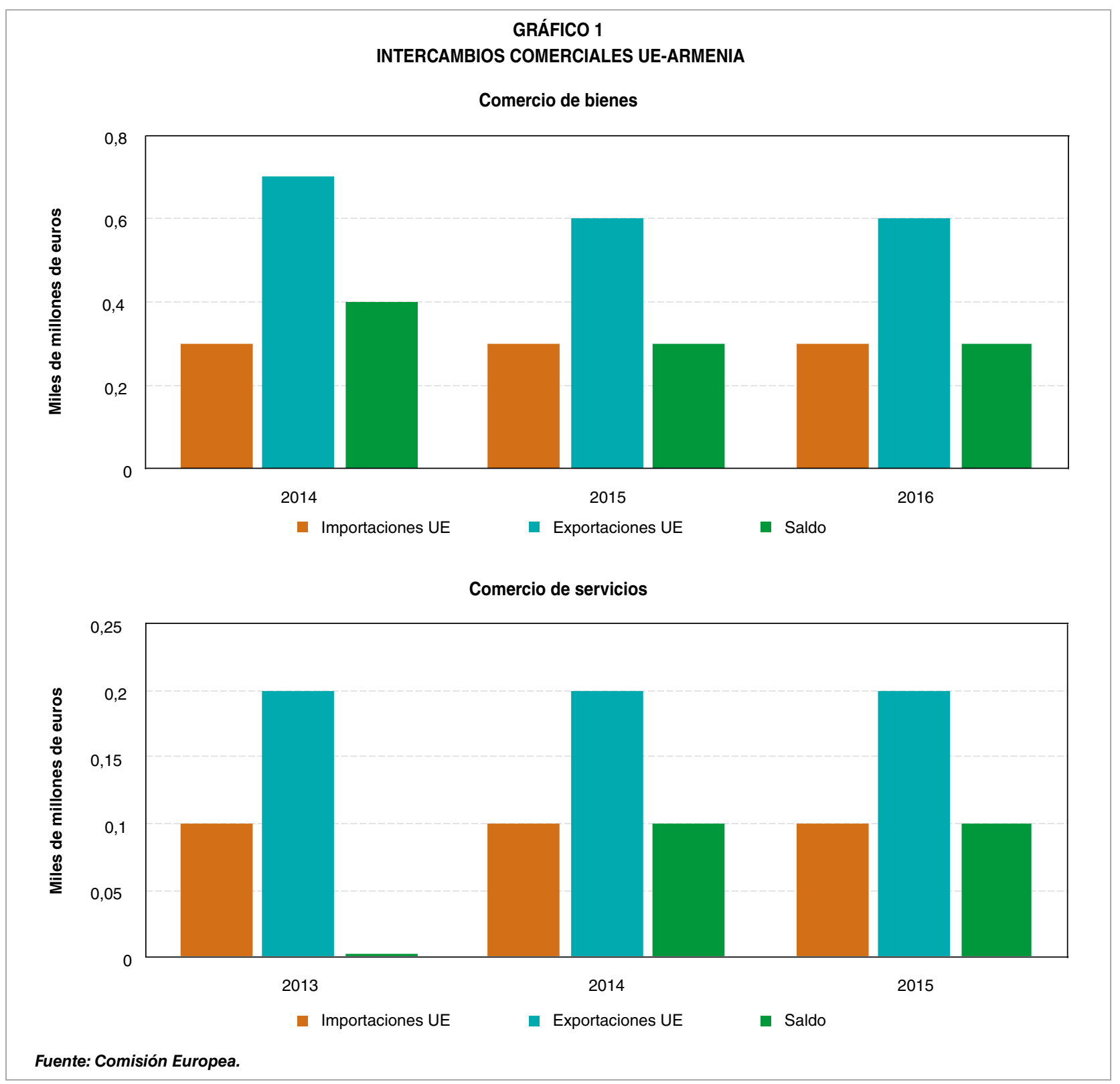


millones de dólares, sobre todo petróleo y gas, y automóviles (CIA, 2017).

El crecimiento medio anual del PIB armenio fue del 10,5 por 100 entre 1999 y 2008. En 2009 su PIB registró una importante caída, del 14,1 por 100, pero a partir de 2010 ha logrado tasas de crecimiento positivas, aunque más moderadas que antes de la última crisis internacional. En 2016 el crecimiento fue muy modesto, del 0,2 por 100, aunque las previsiones del FMI, de abril de 2017 son que el PIB aumente un 2,9 por 100 en 2017 y 2018.

Por último, Armenia se sitúa en el puesto 79 , entre 138 países, en el ranking de competitividad global (World Economic Forum, 2016); en la posición 38 de 190 economías en facilidad de hacer negocios de acuerdo con el Banco Mundial (Doing Business, Banco Mundial, 2017) y en la posición 113, entre 175 países, en el índice de percepción de la corrupción (Transparencia Internacional, 2016).

Las relaciones de Armenia con la UE, al igual que las de Azerbaiyán y Georgia, se enmarcan dentro de la Dimensión Este de la Política Europea de Vecindad. En el caso de Armenia, las bases de su relación jurídica con la UE se fijan en el Acuerdo de Colaboración y de Cooperación que entró en vigor en 1999. El paulatino estrechamiento de lazos entre Armenia y la UE se detendría entre 2014 y 2015 con la entrada de Armenia en la Unión Económica Euroasiática. Desde el 7 de diciembre de 2015 la UE y Armenia negocian un nuevo acuerdo que sustituya al firmado en 1999, teniendo en cuenta las obligaciones derivadas de la adhesión de este Estado a la Unión Económica Euroasiática.

La Unión Europea es el principal socio comercial de Armenia, el comercio entre ambas supone el 29,7 por 100 del comercio total de Armenia. Desglosando estos datos, encontramos que el 39,4 por 100 de las exportaciones armenias tienen a la UE como destinatario, y el 26,5 por 100 de las importaciones de armenia provienen también de la Unión Europea. Las importaciones de la UE desde Armenia consisten fundamentalmente en bienes manufacturados, materias primas, bebidas y tabaco, mientras que las principales exportaciones de la Unión Europea se componen mayoritariamente de maquinaria, bienes manufacturados y productos químicos (Comisión Europea, 2017).

\section{Azerbaiyán}

Tres factores distinguen a Azerbaiyán de Georgia y Armenia. En primer lugar, Azerbaiyán es un Estado de mayoría turca musulmana, más concretamente musulmán chií, si bien el país se define como nación laica. En segundo lugar, y a diferencia de sus vecinos, Azerbaiyán cuenta con importantes depósitos de gas y petróleo, lo que supone el principal sustento de su economía. No obstante, la riqueza proveniente de estas explotaciones se concentra mayoritariamente en manos de una reducida élite. $Y$ este es el tercer factor, la extrema corrupción y el régimen autocrático presente en el país. Si bien ninguno de los tres Estados que conforman el Cáucaso Sur destaca por su salud democrática, las actitudes entre los distintos países varían notablemente. Así, mientras que en Georgia se ve una búsqueda activa de un sistema democrático y Armenia se mantiene como un país con un régimen entre autoritario e híbrido, Azerbaiyán es una república exclusivamente de nombre, porque está dominada por la familia Aliyev.

De acuerdo con la información disponible en Databank del Banco Mundial, Azerbaiyán $\triangleright$ 
es un país de ingreso mediano alto. Con casi 10 millones de habitantes y una edad media de 30,9 años, en 2016 tenía un PIB de 37.848 millones de dólares corrientes. Su renta per cápita $^{2}$ es de 4.760 en dólares corrientes en 2016 y de 15.700 millones de dólares en paridad de poder de compra. Más de un tercio de su producción proviene de la explotación de reservas de productos petrolíferos, lo que explica que su PIB sea superior a sus vecinos del Cáucaso del Sur, pero también supone una gran dependencia de la evolución del mercado mundial de estas commodities. De hecho, desde 2013 el PIB y la renta media en dólares corrientes se han reducido casi a la mitad.

En su estructura productiva destaca el peso de la industria: casi el 50 por 100 de su PIB proviene de este sector y da ocupación al 14 por 100 de la fuerza laboral. La agricultura también tiene una relevancia muy destacada: supone alrededor de un 7 por 100 del PIB y el 37 por 100 del empleo. Por su parte, los servicios contribuyen con un 43 por 100 al PIB, sector en el que está casi el 50 por 100 del empleo (CIA, 2016).

La tasa de paro en Azerbaiyán es reducida, del orden del 5 por 100. Por su parte, la inflación es muy alta, situándose en 2016 en el 12,4 por 100, y las previsiones del FMI de abril de 2017 son que se reduzca levemente pero se mantenga en tasas elevadas en 2017 (10 por 100) y 2018 (8 por 100).

En las relaciones con el exterior, Azerbaiyán ha pasado de registrar un superávit por cuenta corriente muy elevado (más del 20 por 100 en 2009 y en 2010 y del 13,3 por 100 en 2014) a presentar un déficit moderado en los dos últimos años (-0,4 por 100 en 2015 y -3,8 por 100 en 2016). Según las estimaciones realizadas

2 INB per cápita, método Atlas (USD a precios actuales), Banco Mundial. por el FMI, en abril de 2017, Azerbaiyán tendrá un superávit por cuenta corriente equivalente al 1,3 por 100 de su PIB en 2017 y del 3,8 por 100 en 2018.

El valor de sus exportaciones de bienes en 2016 se situó alrededor de los 12.500 millones de dólares, de los cuales más del 90 por 100 procede de las ventas de petróleo y gas, siendo sus principales destinos países miembros de la UE: Italia (20 por 100 del total), Alemania (11 por 100), Francia (7,5 por 100) e Israel (7 por 100). Por su parte, el valor de sus importaciones de bienes es del orden de 8.500 millones de dólares, básicamente maquinaria y equipos, productos alimenticios, metales y productos químicos, siendo sus principales proveedores, aparte de Estados miembros de la UE, Rusia (15 por 100), Turquía (13 por 100) y Japón (6 por 100) (CIA, 2015-2016).

El crecimiento medio anual del PIB de Azerbaiyán fue del 14,6 por 100 entre 1999 y 2008. Los efectos de la crisis financiera internacional sobre su ritmo de crecimiento no fueron tan abruptos como en otros países del Cáucaso, pero sí provocaron una ralentización. En 2016, según estimaciones del FMI, el PIB de Azerbaiyán registró un descenso del 3,8 por 100 en términos reales, sin duda afectado por el descenso del precio petróleo, del que depende en una gran proporción, y de la debilidad del dólar estadounidense en el que se hacen la mayor parte de las ventas de petróleo y gas. Las previsiones de abril de 2017 del FMI son que, en 2017, haya una nueva caída del PIB del 1 por 100 y que en 2018 aumente un 2 por 100 en términos reales.

Al igual que sucede con Armenia, el principal socio comercial de Azerbaiyán es la Unión Europea, siendo las relaciones comerciales reguladas por el Acuerdo de Colaboración y de Cooperación vigente desde 1999. $\square$ 


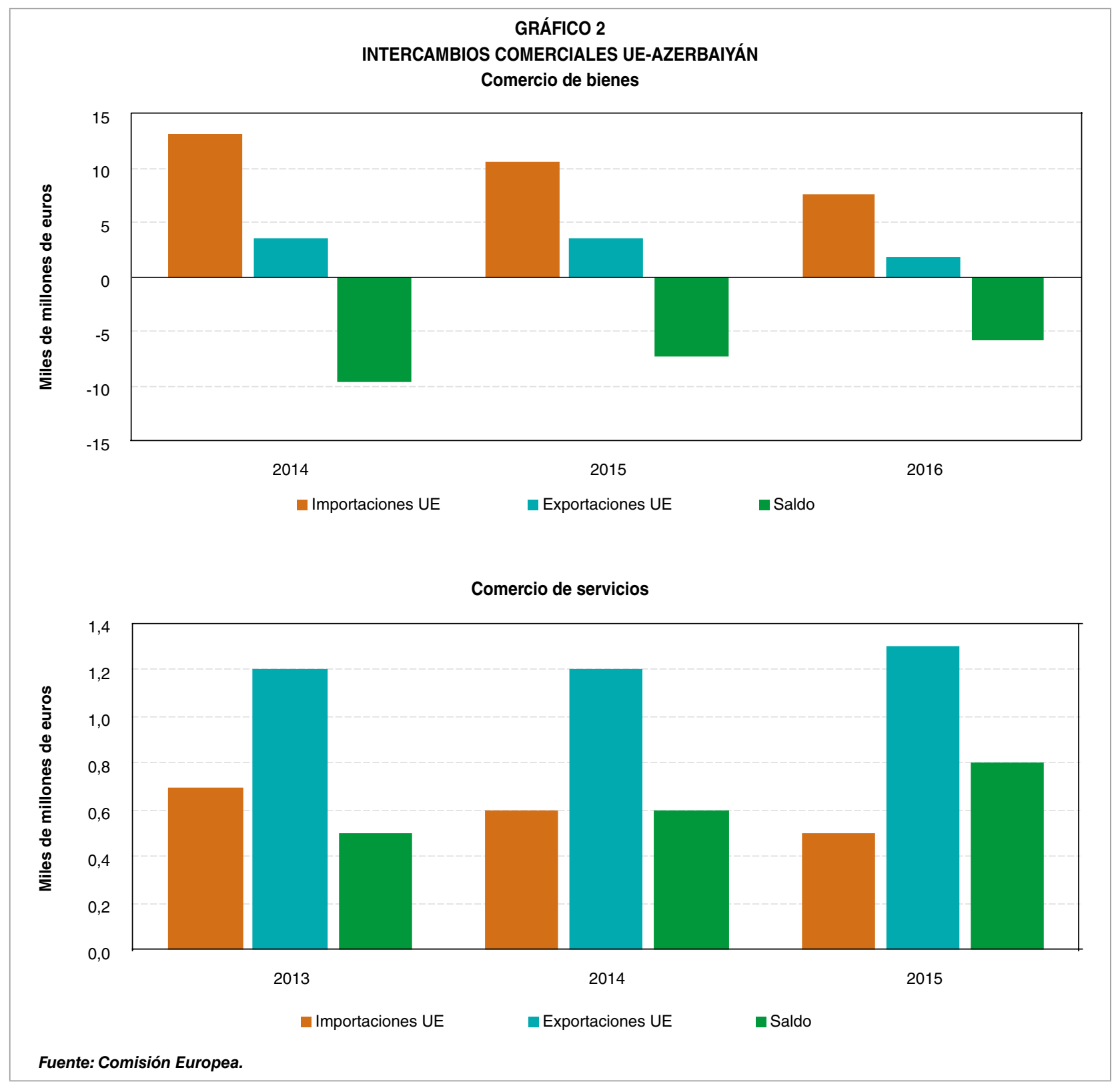

Desde 2010 se trabaja en la negociación de un Acuerdo de Asociación dentro del marco general de la Asociación Oriental. El comercio con la Unión Europea supone un 42,4 por 100 del total del comercio azerí, siendo la Unión el destino del 48,3 por 100 de las exportaciones azeríes, ascendiendo a un 27,7 por 100 del total de sus importaciones aquellas provenientes de la Unión Europea. Las principales exportaciones de Azerbaiyán a la UE son gas y petróleo, seguidas de maquinaria y productos químicos, mientras que de la Unión importa maquinaria, productos manufacturados y productos químicos (Comisión Europea, 2017).

\section{Georgia}

Georgia muestra el carácter más europeísta de los países del Cáucaso Sur. El giro hacia Europa, cuyo origen se suele situar en la llamada «Revolución de las Rosas» supuso $\triangleright$ 
un deterioro de las relaciones entre Georgia y Rusia, hasta el punto de que ésta se posicionó con los rebeldes, primero surosetos y posteriormente abjazos frente a Tblisi, siendo su explícito apoyo militar esencial para la derrota de las fuerzas georgianas en la Guerra de Osetia del Sur en 2008. El bloqueo comercial que Rusia mantiene sobre Georgia desde ese momento ha llevado a este país, hasta entonces muy dependiente de Rusia tanto para sus exportaciones como sus importaciones, a buscar nuevos socios comerciales, como la Unión Europea. Mientras que las relaciones con Azerbaiyán se han caracterizado por su cordialidad desde la independencia de ambos Estados, las relaciones entre Georgia y Armenia se vieron dañadas a raíz de la Guerra de Osetia del Sur, con la postura georgiana de respetar en todo momento la integridad territorial de Azerbaiyán, en referencia al conflicto del Nagorno-Karabaj. No obstante, al resultar una de sus dos únicas fronteras abiertas, buenas relaciones con Georgia son esenciales para Armenia, y pese a sus diferencias, las relaciones entre ambos Estados se mantienen relativamente cordiales.

De acuerdo con la información disponible en Databank del Banco Mundial, Georgia es un país de ingreso mediano bajo. Con algo más de 3,7 millones de habitantes, más de un millón menos que en 1993, y una edad media de 38 años, en 2016 tenía un PIB en dólares corrientes de aproximadamente 14.333 millones de dólares. Su renta per cápita ${ }^{3}$ en 2016 es de 3.810 millones en dólares corrientes y de alrededor de 9.500 millones en paridad de poder de compra, un poco más de una cuarta parte del poder adquisitivo de los españoles.

3 INB per cápita, método Atlas (USD a precios actuales), Banco Mundial.
La agricultura tiene todavía un elevado peso en su estructura productiva: supone el 9 por 100 del PIB y más del 55 por 100 del empleo en Georgia. La industria genera el 21,5 por 100 del PIB y da empleo al 9 por 100 de los ocupados y los servicios suponen el 68,5 por 100 y el 36 por 100 del empleo (CIA, 2016).

La tasa de paro se sitúa en torno al 12 por 100, y casi un 10 por 100 de su población está por debajo de la línea de la pobreza. La inflación en 2016 fue moderada, 2,1 por 100, pero ha repuntado en el año en curso. Las previsiones de abril de 2017 del FMI son que la inflación en 2017 será del 5,7 por 100 y en 2018 del 2,4 por 100. Por su parte, el déficit público en 2016 fue del 2 por 100 del PIB.

Georgia registra tradicionalmente un déficit en sus intercambios comerciales, con una tasa de cobertura (valor exportaciones /importaciones) del orden del 30 por 100 en los últimos años, y de su balanza por cuenta corriente, que arroja un déficit superior al 10 por 100 de su PIB. EI FMI, en sus previsiones de abril de 2017, espera que en 2017 Georgia registre un déficit por cuenta corriente del 12,9 por 100 del PIB y del 12,5 por 100 en 2018. Este déficit exterior es financiado, principalmente, con las entradas de inversiones extranjeras y ayudas procedentes de organismos internacionales, además de remesas enviadas por emigrantes.

El valor de sus exportaciones de bienes en 2016 fue de 2.926 miles de millones de dólares, básicamente de materias primas, productos agrícolas y minerales, y vehículos, siendo sus principales destinos, además de la Unión Europea, Azerbaiyán (11 por 100 del total), Bulgaria (10 por 100), Turquía (8,5 por $100)$, Armenia (8 por 100), Rusia (7,5 por 100) y China (6 por 100). Por su parte, el valor de sus importaciones de bienes es de 6.800 miles de millones de dólares, fundamentalmente $\triangleright$ 
de petróleo y gas, automóviles, maquinaria y componentes, así como medicamentos. Sus principales socios comerciales son, pues, los países de su entorno, además de China y algunos países de la UE (Alemania, Países Bajos o Reino Unido), que han ido progresivamente aumentando su presencia (CIA, 2016).

Después de registrar un crecimiento del PIB de más del 6 por 100 entre 1999 y 2008, gracias a la entrada de inversión extranjera y al aumento del gasto público, Georgia registró una notable contracción, con un descenso de su PIB del 4 por 100 en 2009 como consecuencia del conflicto con Rusia y los efectos derivados de la crisis financiera internacional. A partir de 2010 se ha recuperado la economía georgiana, con tasas de aumento del PIB que se han situado entre el 3 y el 4,5 por 100 en los tres últimos ejercicios, aunque no se han recuperado los niveles de entrada de inversión extranjera y el desempleo se mantiene elevado. Esta recuperación se basa en los paquetes de estímulo del FMI y de otros organismos internacionales, en la mejora de sus exportaciones y en los proyectos de infraestructuras de transportes de hidrocarburos entre Azerbaiyán y el Mediterráneo. En el primer trimestre de 2017 la economía georgiana ha registrado un repunte en su crecimiento, del orden del 5 por 100 en tasa anual, gracias a una mejora de sus exportaciones y unas mayores entradas de remesas de inmigrantes. Según las previsiones del FMI realizadas en abril de 2017, el crecimiento del PIB en Georgia en 2017 será del 3,5 por 100 y del 4 por 100 en 2018.

Por último, Georgia se sitúa en el puesto 59, entre 138 países, en el ranking de competitividad global (World Economic Forum, 2016); en la posición 16 de 190 economías en facilidad de hacer negocios (Doing Business, Banco Mundial, 2017) y en la posición 44, entre 175 países, en el índice de percepción de la corrupción (Transparencia Internacional, 2016). Georgia presenta, pues, un entorno amigable a las empresas extranjeras, con una fiscalidad baja, una legislación laboral flexible y unos costes de funcionamiento reducidos.

A principios de 2017, Georgia y el Fondo Monetario Internacional llegaron a un acuerdo para un programa trianual de financiación de 285 millones de dólares, destinados a la reforma del sistema de pensiones, a la creación de un fondo de garantía de depósitos bancarios y al desarrollo del mercado de capitales, que puede aportar confianza a los inversores internacionales en Georgia (La Vanguardia, 2017).

En virtud de sus esfuerzos por liberalizar su economía y promover una cultura democrática, y por su talante europeísta, las relaciones entre la Unión Europea y Georgia se rigen por un nuevo Acuerdo de Asociación que entró en vigor el 1 de julio de 2016. Incluido dentro de este acuerdo se presenta un régimen comercial preferente, el Deep and Comprehensive Free Trade Area.

Tal y como sucede con Armenia y Azerbaiyán, la Unión Europea es el principal socio comercial de Georgia, suponiendo un 32,6 por 100 del total. Si bien la Unión Europea es un socio comercial fundamental para Georgia, para la UE el comercio con Georgia supone apenas un 0,1 por 100 del total. El valor total de las exportaciones de la UE a Georgia en 2015 se sitúa en torno a los 1.840 millones de euros, siendo productos minerales, maquinaria y productos químicos las principales exportaciones. Por su parte, en 2015, Georgia exportó a la Unión productos minerales, maquinaria, productos agrícolas, productos químicos y metales comunes por un valor de 742 millones de euros (Comisión Europea, 2017). 


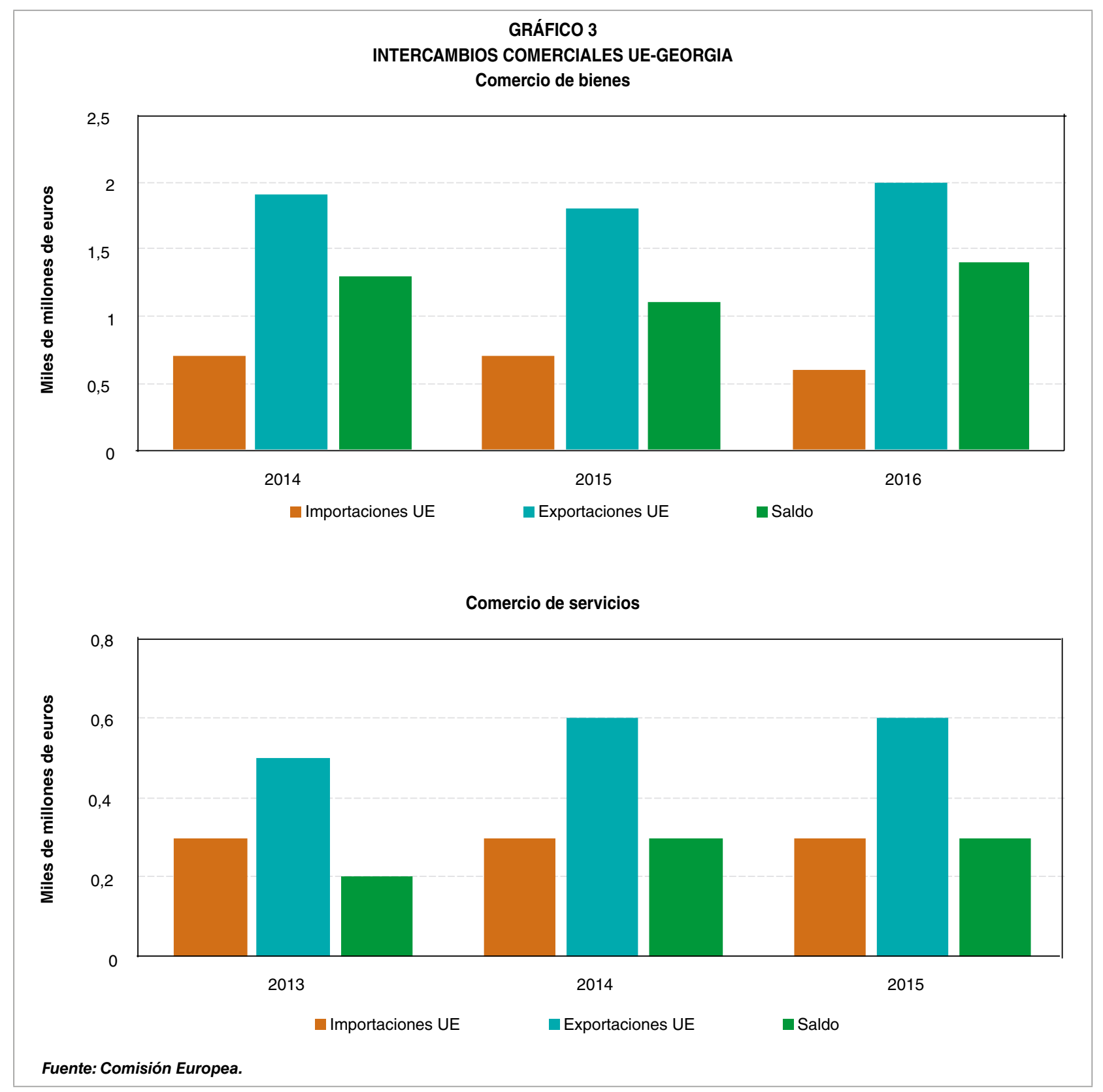

\section{Conclusión}

Los tres países que conforman el Cáucaso Sur se enfrentan a los mismos problemas que la mayoría de Estados surgidos del desmembramiento de la Unión Soviética. Pese a ser repúblicas los tres, únicamente Georgia parece mostrar una vocación democrática, Armenia se aproxima peligrosamente a un régimen autocrático y Azerbaiyán es, claramente, un régimen dictatorial. Además, Armenia y Azerbaiyán se encuentran en un estado de frágil paz, con las relaciones diplomáticas completamente rotas. Por su parte, Georgia está pagando el precio de su vocación europeísta con el apoyo ruso a las provincias rebeldes de Abjasia y Osetia del Sur. Los tres Estados muestran un desarrollo económico todavía precario, con un elevado porcentaje de la población empleada en el sector primario, pero a diferencia de Georgia y $\triangleright$ 
Armenia, Azerbaiyán goza de unas reservas de gas y petróleo que lo convierten en el Estado más rico de la región, si bien la falta de diversificación de su economía y la concentración de la riqueza en unos pocos individuos evidencian la debilidad del sistema económico azerí.

Los tres países que conforman el Cáucaso del Sur han mostrado un claro interés por acrecentar sus lazos con la Unión Europea, y ésta, mediante la Política Europea de Vecindad, trata de extender sus intereses económicos a la par que defiende los principios sociales fundamentales de la Unión. No obstante, la influencia europea se enfrenta a otros actores regionales, como son Turquía, Irán y, ante todo, Rusia. Hasta qué punto será capaz la Unión Europea de tener un papel significativo en la región, sea desde un punto de vista económico o desde uno político, dependerá en gran medida de su capacidad de mostrar de forma clara a estos Estados las ventajas de una mayor asociación con la Unión, en detrimento de una más cercana relación con una o varias de estas potencias.

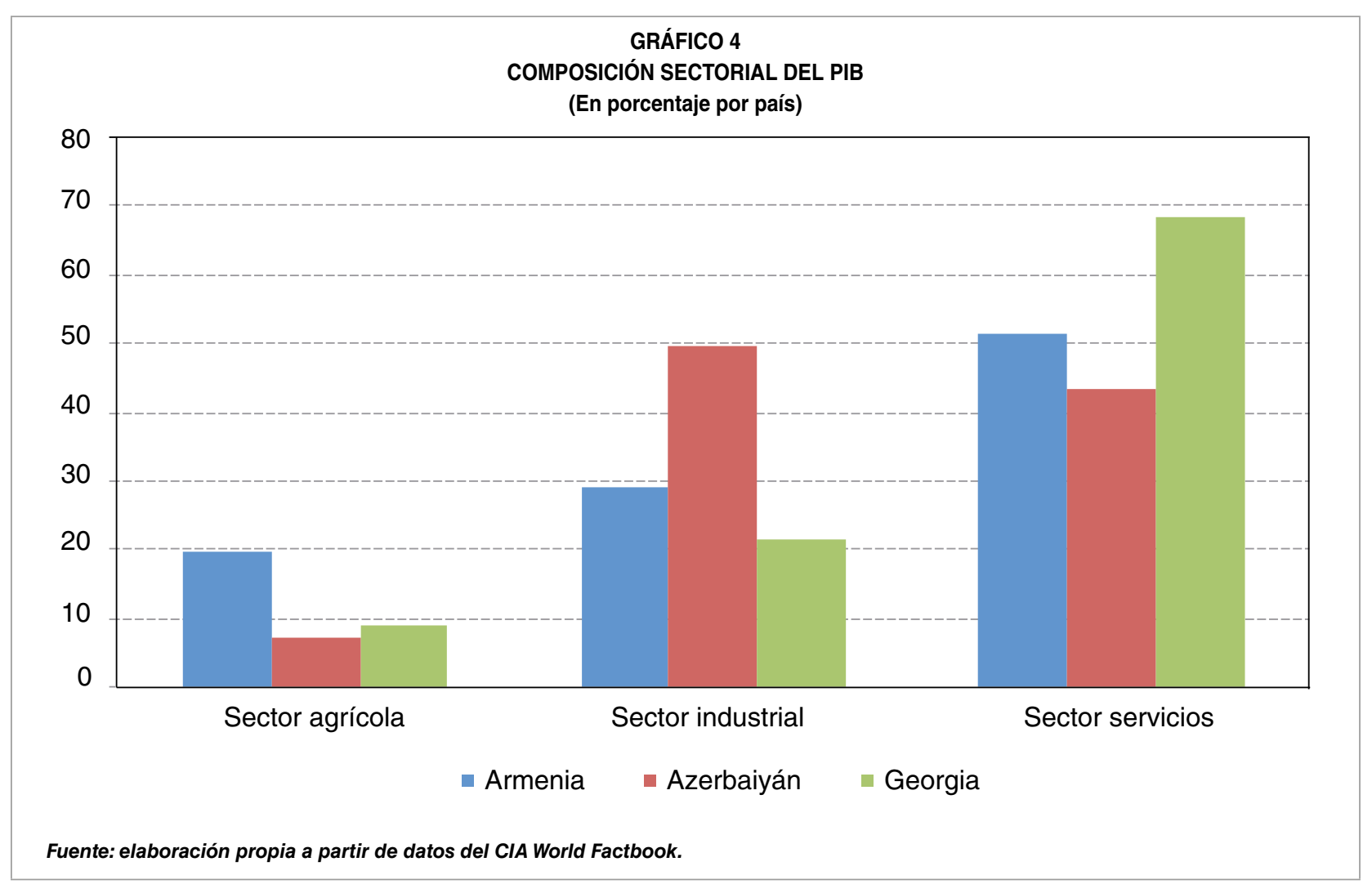

TABLA 1

PRINCIPALES INDICADORES POR PAÍS (2015)

\begin{tabular}{|l|c|c|c|c|}
\hline \multicolumn{1}{|c|}{ País } & Población & Edad media & $\begin{array}{c}\text { PIB (en millones } \\
\text { de dólares) }\end{array}$ & $\begin{array}{c}\text { Renta per cápita } \\
\text { PPA }\end{array}$ \\
\hline Armenia & 3.017 .712 & 34,6 & 10,529 & 3.880 \\
Azerbaiyán & 9.649 .341 & 30,9 & 53,047 & 6.560 \\
Georgia & 3.717 .100 & 38,0 & 13,965 & 4.120 \\
\hline \multicolumn{2}{|l}{ Fuente: elaboración propia a partir de datos del Banco Mundial y CIA World Factbook. } \\
\hline
\end{tabular}




\section{Bibliografía}

[1] AHMADOV, I.; MAMMADOV, J.; ASLANLI, K. y GULIYEV, F. (2016). «Low Oil Prices: Economic and Social Implications for Azerbaijan", Caucasus Analytical Digest n. 83, 21 de abril. Ed. Eurasia Extractive Industries Knowledge Hub y Jeronim Perović.

[2] EUROPEAN COMISSION (2017). Trade, Armenia. Disponible en: http://ec.europa.eul trade/policy/countries-and-regions/countries/ armenial

[3] EUROPEAN COMISSION (2017). Trade, Azerbaijan. Disponible en: http://ec.europa.eu/trade/policy/countries-and-regions/ countries/azerbaijan/

[4] EUROPEAN COMISSION (2017). Trade, Georgia. Disponible en: http://ec.europa.eu/ trade/policy/countries-and-regions/countries/ georgial

[5] FONDO MONETARIO INTERNACIONAL (2016). Middle East and Central Asia Regional Outlook (octubre). Washington D.C. Disponible en: https://www.imf.org/external/ pubs/ft/reo/2016/mcd/mreo1016.htm

[6] FONDO MONETARIO INTERNACIONAL (2017). Word Economic Outlook (abril). Washington D.C.Disponible en: http://www.imf. org/en/Publications/WEO/Issues/2017/04/04/ world-economic-outlook-april-2017

[7] «Georgia acuerda con el FMI un programa de asistencia de 285 millones dólares » ( 1 de marzo de 2017) (en línea). La Vanguardia. Disponible en: http://www.lavanguardia. com/politica/20170301/42424282999/ georgia-acuerda-con-el-fmi-un-programade-asistencia-de-285-millones-dolares. html

[8] «Joint Declaration of the Eastern Partnership Summit» (Riga, 21-22 de mayo de 2015) (en línea). Disponible en: https://eeas.europa.eu/sites/eeas/files/ riga-declaration-220515-final_en.pdf

[9] «Georgia, mirando a Occidente» (5 de mayo de 2015) (en línea). El Exportador, revista para la internacionalización. Disponible en: http://www.icex.es/icex/es/Navegacionzona-contacto/revista-el-exportador/mundo/ REP2015408042.html

[10] MIKAELIAN, H.; GULIYEV, F. y RUDAZ, P. (2015). «Informal Economy», Caucasus Analytical Digest n.ำ 75, 17 de julio. Ed. Philippe Rudaz.

[11] MINISTERIO DE ASUNTOS EXTERIORES Y COOPERACIÓN (2017). Ficha país: Azerbaiyán. Disponible en: http://www.icex. es/icex/es/Navegacion-zona-contacto/revista-el-exportador/mundo/REP2015408042. $h t m l$

[12] SAPAROV, A.; MAMMADOVA, S.; CHETERIAN, V. y RUMYANSEV,S. (2016). "Karabakh Conflict», Caucasus Analytical Digest n. -84 , junio. Ed. Jeronim Perović.

[13] «Country Report: Armenia» (abril de 2017) (en línea). The Economist Intelligence Unit.

[14] «Country Report: Azerbaijan» (febrero de 2017) (en línea). The Economist Intelligence Unit.

[15] «Country Report: Georgia» (marzo de 2017) (en línea). The Economist Intelligence Unit. 


ISSN 0214-8307

\section{SUSCRIPCIÓN ANUAL}

\begin{tabular}{|c|c|c|c|}
\hline \multicolumn{2}{|c|}{ BOLETÍN ECONÓMICO DE INFORMACIÓN COMERCIAL ESPAÑOLA (12 NÚMEROS) } \\
\hline & $\begin{array}{c}\text { ESPAÑA } \\
\mathbf{1} \text { año }\end{array}$ & $\begin{array}{c}\text { UNIÓN EUROPEA } \\
\mathbf{1} \text { año }\end{array}$ & $\begin{array}{c}\text { RESTO DEL } \\
\text { MUNDO } \\
\mathbf{1} \text { año }\end{array}$ \\
\hline SUSCRIPCIÓN & $65,00 €$ & $85,00 €$ & $85,00 €$ \\
\hline $\begin{array}{c}\text { Gastos de envío } \\
\text { España }\end{array}$ & $5,76 €$ & $24,36 €$ & $30,00 €$ \\
\hline $\begin{array}{c}\text { Más 4\% de IVA. } \\
\text { Excepto Canarias, Ceuta y Melilla }\end{array}$ & $2,83 €$ & & $115,00 €$ \\
\hline TOTAL & $\mathbf{7 3 , 5 9} €$ & $\mathbf{1 0 9 , 3 6} €$ & \\
\hline & & & \\
\hline
\end{tabular}

\section{EJEMPLARES SUELTOS}

\begin{tabular}{|c|c|c|c|}
\hline BOLETÍN ECONÓMICO & DE INFORMACIÓN & COMERCIAL ESPAÑOL & \\
\hline & $\begin{array}{l}\text { ESPAÑA } \\
1 \text { ejemplar }\end{array}$ & $\begin{array}{l}\text { UNIÓN EUROPEA } \\
1 \text { ejemplar }\end{array}$ & $\begin{array}{c}\text { RESTO DEL } \\
\text { MUNDO } \\
1 \text { ejemplar }\end{array}$ \\
\hline NÚMERO SUELTO & $7,00 €$ & $9,00 €$ & $9,00 €$ \\
\hline $\begin{array}{l}\text { Gastos de envío } \\
\text { España }\end{array}$ & $0,48 €$ & $2,03 €$ & $2,50 €$ \\
\hline $\begin{array}{l}\text { Más } 4 \% \text { de IVA. } \\
\text { Excepto Canarias, Ceuta y Melilla }\end{array}$ & $0,30 €$ & & \\
\hline TOTAL & $7,78 €$ & $11,03 €$ & $11,50 €$ \\
\hline \multirow[t]{2}{*}{ BOLETÍN ECONÓMICO } & DE INFORMACIÓN & COMERCIAL ESPAÑOL & \\
\hline & $\begin{array}{l}\text { ESPAÑA } \\
1 \text { ejemplar }\end{array}$ & $\begin{array}{l}\text { UNIÓN EUROPEA } \\
1 \text { ejemplar }\end{array}$ & $\begin{array}{c}\text { RESTO DEL } \\
\text { MUNDO } \\
1 \text { ejemplar }\end{array}$ \\
\hline $\begin{array}{l}\text { NÚMERO SUELTO } \\
\text { EXTRAORDINARIO }\end{array}$ & $12,00 €$ & $15,00 €$ & $15,00 €$ \\
\hline Gastos de envío España & $0,48 €$ & $2,03 €$ & $2,50 €$ \\
\hline $\begin{array}{c}\text { Más } 4 \% \text { de IVA. } \\
\text { Excepto Canarias, Ceuta y Melilla }\end{array}$ & $0,50 €$ & & \\
\hline TOTAL & $12,98 €$ & $17,03 €$ & $17,50 €$ \\
\hline
\end{tabular}

\section{DATOS}

Nombre y apellidos

Empresa

Domicilio

D.P.

N.I.F.

Teléf.

Email

\section{DATOS DEL EDITOR:}

NIF:S2800568D

Transferencia a la cuenta de ingresos por venta de publicaciones del Ministerio de Economía y Competitividad.

IBERCAJA. Calle Alcalá 29. 28014 MADRID (ESPAÑA) CÓDIGO CUENTA CLIENTE: 2085-9252-07-0330598330 CÓDIGO BIC DE IBERCAJA: CAZRES2Z

IBAN: ES47 2085-9252-07-0330598330

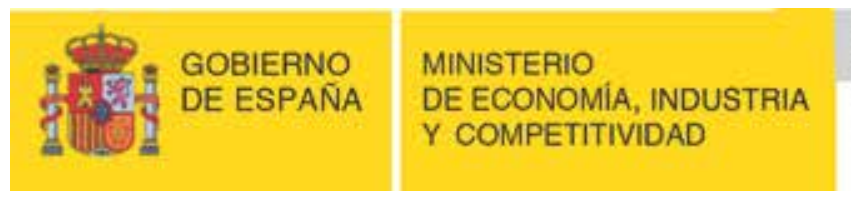

SUBSECRETARIA

SECRETARIA GENERAL TÉCNICA

SUBDIRECCION GENERAL DE

ESTUDIOS, INFORMACION Y PUBLICACIONES

Suscripciones y ventas por correspondencia:

Paseo de la Castellana, $1628^{a}$ Planta 28046 Madrid. Teléfono 916037993 / 97

Suscripciones a través de la página web del Ministerio de Economía, Industria y Competitividad distribucionpublicaciones@mineco.es 



\section{NORMAS DE ESTILO DE PUBLICACIÓN}

La persona o personas interesadas en presentar un artículo para su publicación en el Boletín de Información Comercial Española (BICE) deberán enviar el artículo en formato Microsoft Word a la dirección de correo electrónico revistasice.sscc@comercio.mineco.es

El documento debe cumplir las siguientes características:

1. Ser material original no publicado ni presentado en otro medio de difusión.

2. La extensión total del trabajo (incluyendo cuadros, gráficos, tablas, notas, etcétera) no debe ser inferior a 15 páginas ni superior a 20. La fuente será Times New Roman, tamaño 12 y espaciado doble. Estar paginado en la parte inferior derecha de cada página.

3. En la primera página se hará constar el título del artículo que deberá ser breve, claro, preciso e informativo y la fecha de conclusión del mismo. Nombre y dos apellidos del autor o autores, filiación institucional, dirección, teléfono y correo electrónico de cada uno de ellos, así como la forma en que desean que sus datos aparezcan.

4. En la segunda página del texto se incluirá:

- El título.

- Un resumen del trabajo con una extensión máxima de 10 líneas con la siguiente estructura: objetivo, método y principal resultado o conclusión.

- De 2 a 6 palabras clave que no sean coincidentes con el título.

- De 1 a 5 códigos de materias del Journal of Economic Literature (clasificación JEL) para lo cual pueden acceder a la siguiente dirección electrónica:

https://www.aeaweb.org/jel/guide/jel.php

5. En las siguientes páginas se incluirán el texto, la información gráfica y la bibliografía con la siguiente organización.

- Se incluirá, por este orden, introducción, desarrollo, conclusiones y bibliografía y anexos si los hubiera. Los apartados y subapartados se numerarán en arábigos respondiendo a una sucesión continuada utilizando un punto para separar los niveles de división, según el siguiente modelo:

\section{Título del apartado}

\subsection{Título del apartado}

\subsubsection{Título del apartado}

\section{Título del apartado}

- Las notas de pie de página irán integradas en el texto y su contenido debe estar al final de su misma página en tamaño 10 y espacio sencillo.

- En un archivo Excel independiente se incluirá la representación gráfica (cuadros, gráficos, diagramas, figuras, etc.), que debe llevar título, estar numerada y referenciada en el texto.

En la parte inferior se incluirá la fuente de información y/o notas aclaratorias.

- Las citas de libros y artículos en el texto, se indicarán entre paréntesis con el apellido del autor y el año. Ej.: (Martínez, 1991).

- Las referencias a siglas deben ir acompañadas, en la primera ocasión en que se citen, de su significado completo.

- La bibliografía se ordenará alfabéticamente siguiendo las normas de la American Psychological Association (Harvard-APA): http://cibem.org/paginas/img/apa6.pdf

Libros

APELLIDOS, A.A. (año de publicación). Título del libro (edición) (volumen). Ciudad: Editorial.

Artículo en revista científica

APELLIDOS, A.A. (año de publicación). «Título del artículo». Título de la revista, volumen (número), números de páginas.

\section{Documento en línea}

APELLIDOS, A.A. u ORGANISMO (año, mes de publicación). Título, [en línea]. Ciudad: Editorial. Disponible en:

http://cenamb.rect.ucv.ve/siamaz/dicciona/canaima/canaima2.htm [Recuperado: 2000, 3 de junio]. 
